Bundesgesundheitsbl 2014 · 57:557-567

DOI 10.1007/s00103-013-1925-9

Online publiziert: 25. April 2014

(c) Springer-Verlag Berlin Heidelberg 2014

C. Frank · M. Faber · W. Hellenbrand · H. Wilking · K. Stark

Robert Koch-Institut, FG35, Berlin

\title{
Wichtige, durch Vektoren übertragene Infektionskrankheiten beim Menschen in Deutschland
}

\section{Epidemiologische Aspekte}

Zahlreiche Krankheitserreger werden durch Vektoren übertragen. Als Vektoren bezeichnet man lebende Organismen, die Krankheitserreger von einem infizierten Tier oder Menschen auf andere Menschen (oder Tiere) übertragen. $\mathrm{Zu}$ den wichtigsten Vektoren zählen Arthropoden (Stechmücken, Zecken, Läuse u. a.) und auch Nagetiere. Für Deutschland spielen vor allem die endemischen Vektor-übertragenen Infektionserreger eine wichtige Rolle wie die durch Zecken übertragenen Erreger der LymeBorreliose und Frühsommermeningoenzephalitis (FSME) oder die durch Nagetiere übertragenen Hantaviren oder die Erreger der Leptospirose. Aber auch die nach Deutschland importierten, durch Stechmücken übertragenen Erreger von Malaria, Denguefieber, Chikungunyafieber und West-Nil-Fieber sind von wachsender Bedeutung. Sie kommen in vielen Regionen der Welt vor, und die Verhütung bzw. Früherkennung und Therapie der durch sie verursachten Krankheiten stellen eine Herausforderung für die medizinische Versorgung dar. Im Zusammenhang mit der zunehmenden Ausbreitung invasiver Mückenarten in Europa und dem Klimawandel wird die Frage nach dem Risiko einer autochthonen Erregerübertragung (d. h. ortsständig in Deutschland) relevant. Im Folgenden geben wir neben jeweils kurzen Hintergrundinformationen einen Überblick über die epidemiologische Situation und die Meldedaten gemäß Infektionsschutzgesetz (IfSG) bei ausgewählten, Vektorübertragenen Erregern bzw. den von ih- nen verursachten Krankheiten. Sie sind aus Sicht der Autoren für Deutschland besonders relevant und wurden ausgewählt, weil entweder eine Erregerübertragung in Deutschland eine beträchtliche Krankheitslast verursacht und folglich wichtige Aspekte der Prävention und Kontrolle berührt werden (Lyme-Borreliose, FSME, Hantavirus-Erkrankungen), weil im Rahmen der Meldepflicht eine größere Zahl an importierten Infektionen erfasst wird und die Frage nach möglichen autochthonen Infektionen besteht (Malaria, Dengue, Chikungunya) oder weil das Vorkommen von potenziellen Erregervektoren und von Reservoirtieren (Vögel) in Deutschland und die sich verschärfende epidemiologische Situation in den Nachbarländern eine besondere Aufmerksamkeit erfordert (West-Nil-Virus).

\section{Malaria}

Die Malaria wird durch Protozoen der Gattung Plasmodien verursacht. Es existieren 4 humanpathogene Spezies: Plasmodium (P.) falciparum (Malaria tropica), $P$. ovale und P. vivax (Malaria tertiana), P. malariae (Malaria quartana). In letzter Zeit hat P. knowlesi, ein Malariaerreger bei südostasiatischen Affen, in mehreren Ländern schwere Erkrankungen auch bei Menschen verursacht. Etwa 40\% der Weltbevölkerung in den (Sub-)Tropen leben in Malaria-Endemiegebieten, und jedes Jahr treten dort über 200 Mio. Malariaerkrankungen mit über 600.000 Todesfällen auf. Die Plasmodien werden durch weibliche Stechmücken der
Gattung Anopheles übertragen. Die Inkubationszeit variiert: Bei $P$. falciparum umfasst sie 7 bis 28 Tage, bei $P$. vivax/P. ovale 12 bis 18 Tage (aber auch Monate), bei P. malariae 3 bis 7 Wochen. Bei allen Formen kann die Infektion zunächst auch latent verlaufen und sich erst nach Monaten manifestieren. Bei der klinischen Symptomatik steht in der Regel das Fieber im Vordergrund. Es können weitere Symptome hinzutreten (z. B. Kopf- und Gliederschmerzen, gastrointestinale Symptome, Anämie). Bei der Malaria tropica kann es unbehandelt rasch zu einer hohen Parasitämie und zu komplizierten, teilweise letalen Verlaufsformen mit Multiorganversagen kommen. Besonders gefährdet sind Personen ohne Malaria-(Teil-)Immunität in den Endemiegebieten, inklusive Reisenden aus Nicht-Endemiegebieten - vor allem Kinder, Schwangere und Personen mit eingeschränkter Immunabwehr [1].

Bei jeder Person, bei der während des Aufenthaltes in einem Endemiegebiet oder nach der Rückkehr aus einem solchen unklares Fieber auftritt, besteht zunächst Malariaverdacht, der eine rasche diagnostische Klärung erfordert. Zur Behandlung stehen wirksame Medikamente zur Verfügung. Abhängig vom jeweiligen Malariarisiko sind bei Reisen in Endemiegebiete eine Chemoprophylaxe und Expositionsprophylaxe angezeigt.

In Deutschland gilt nach dem IfSG eine Meldepflicht für den Labornachweis von Plasmodien-Spezies, die Malaria verursachen (IfSG $\$ 7$ Abs. 3). Die Meldung erfolgt durch das Labor nicht-namentlich an das Robert Koch-Institut (RKI). 


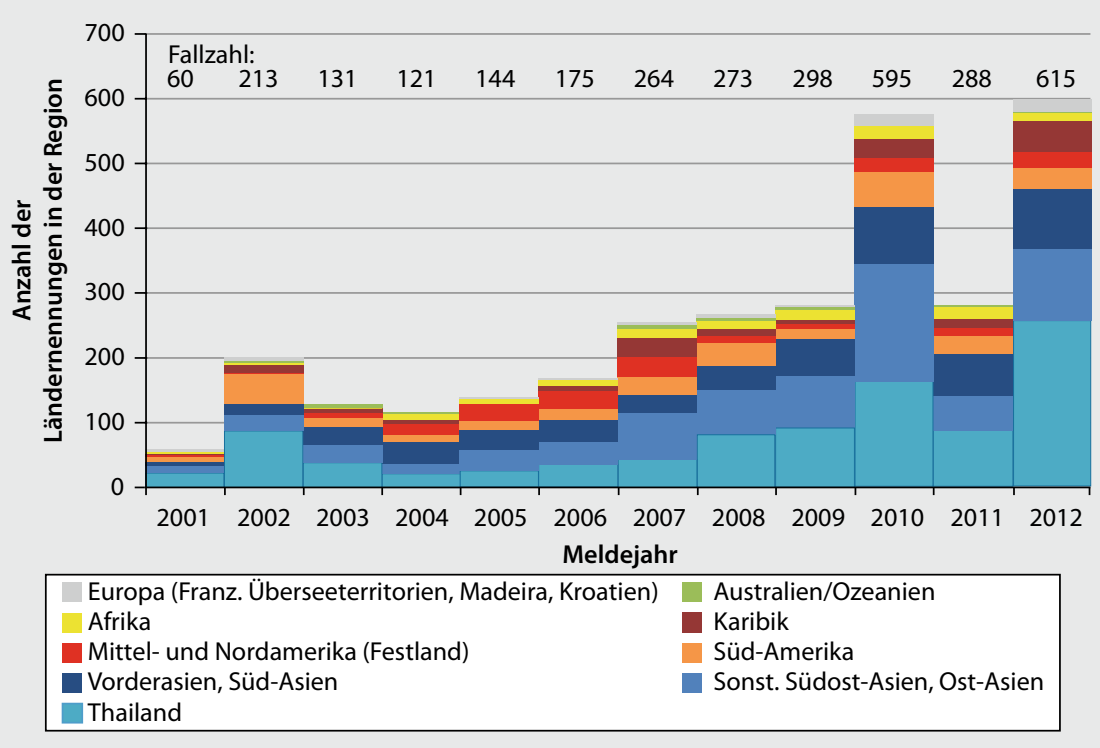

Abb. $1 \Delta$ In Deutschland diagnostizierte und an das RKI übermittelte Denguefieber-Erkrankungen (nach RKI Referenzdefinition) ausgewertet nach den Ländern, in denen diese Infektionen erworben wurden; Zeitraum: 2001 bis einschließlich 2012, n=3061 Landesnennungen bezogen auf 3177 Fälle

Zusätzliche Daten zu Demografie, Reiseland, Klinik u. a. werden ebenfalls anonymisiert über spezielle Meldebögen vom behandelnden Arzt übermittelt.

Die Fallzahlen gingen in Deutschland von über 1000 importierten Fällen 2001 auf jährlich zwischen 500 und 600 Fälle seit 2006 zurück (2012: 547 Malariafälle) [2]. Am häufigsten erfolgte eine Infektion mit Malaria-Plasmodien in Afrika (2012: 83\%), gefolgt von Asien (2012: $17 \%)$. Dies entspricht dem Bild der letzten Jahre. Lateinamerika trat als Infektionskontinent eher selten in Erscheinung und Australien/Ozeanien und Südeuropa nur in Ausnahmefällen. Die wichtigsten Infektionsländer liegen vor allem in Westafrika. In manchen Jahren werden aus bestimmten Ländern überproportional viele Malaria-Erkrankungen importiert. Dies betraf 2012 Pakistan mit 33 importierten Fällen (Vorjahre: 0 bis 8 Fälle) [3]. Solche Verschiebungen können unterschiedliche Ursachen haben (z. B. Veränderungen in der epidemiologischen Situation und der Malariakontrolle im Infektionsland, erhöhte Migration, verändertes Reiseverhalten).

Die am häufigsten nachgewiesene Erregerspezies ist $P$. falciparum (2012: 73\%), gefolgt von $P$. vivax (2012: 14\%). Im Jahr 2012 verstarben in Deutschland 4 Patienten an der Malaria (0,7\%). In den Vorjah- ren (seit 2007) wurden hier jährlich 1 bis 3 malariabedingte Todesfälle registriert.

In Deutschland ist die Malaria eine klassische importierte Infektionskrankheit. Bis Mitte des 20. Jahrhunderts war sie allerdings auch in bestimmten Regionen Deutschlands endemisch.

Es kommen auch hierzulande weiterhin Anopheles-Mücken vor, die theoretisch Plasmodien übertragen könnten [4, 5]. Die Vektorkompetenz der in Deutschland nachgewiesenen Anopheles-Arten ist allerdings derzeit unklar. Im Rahmen der globalen Erwärmung könnten effizientere Vektoren für die Erreger der Malaria nach Europa vordringen, und es könnten sich die Entwicklungsbedingungen für diese in den Mücken verbessern. In Ausnahmefällen wurde in Deutschland in den letzten Jahrzehnten eine autochthone und wahrscheinlich durch Mücken übertragene Malaria-Infektion beschrieben, zuletzt 1997 bei 2 Patienten in einem Krankenhaus im Ruhrgebiet, in dem zeitgleich ein Malaria-Patient stationär behandelt wurde [6]. Seltene Einzelfälle von autochthoner Malaria in Deutschland sind auch in Zukunft nicht auszuschließen, größere Ausbrüche oder sogar eine längerfristige Etablierung des Malaria-Erregers sind aber äußerst unwahrscheinlich. Die Gründe hierfür sind neben den verschlechterten Reproduktionsbedingun- gen für die Anopheles-Mücken in vielen Gebieten (Trockenlegen von Sumpfgebieten etc.) vor allem der hohe medizinische Standard (Früherkennung und effiziente Therapie bei Malaria-Erkrankten und damit Verhinderung von übertragungsfähigen Erregerreservoirs).

\section{Denguefieber}

Durch einen der 4 Serotypen des Denguevirus (DENV, Familie Flaviviren) wird das Denguefieber hervorgerufen. Als Vektor für das Virus fungiert die Gelbfiebermücke Aedes aegypti; auch die Asiatische Tigermücke Aedes albopictus kann als Vektor fungieren (für Stechmücken der Gattung Aedes wird auch der alternative $\mathrm{Na}$ me Stegomyia verwendet).

Zumeist führt die Infektion zu einer selbstlimitierenden Erkrankung. Nach einer Inkubationszeit von meist 3 bis 7 Tagen beginnt die Krankheit abrupt mit hohem Fieber, Kopf- und Gliederschmerzen. Häufig kommt ein Hautausschlag hinzu. Nach ca. 1 Woche bilden sich die Symptome in den meisten Fällen zurück. Bei einer kleinen Minderheit der Patienten (vor allem bei Kindern und jungen Erwachsenen) entwickeln sich nach einigen Tagen entweder hämorrhagische Manifestationen (Dengue-hämorrhagischesFieber, DHF) und/oder eine systemische erhöhte Gefäßdurchlässigkeit (Vascular-Leak-Syndrom), verbunden mit Blutdruckabfall und Kreislaufschock (Dengue-Schock-Syndrom, DSS) mit z. T. tödlichem Verlauf [7]. Eine konsekutive Infektion mit einem zweiten DENV-Serotyp erhöht die Wahrscheinlichkeit eines schweren Verlaufs [8].

Zugelassene Impfstoffe gegen DENV gibt es bislang nicht, ebenso wenig spezifische Chemotherapeutika. Präventiv wirksam ist nur die Vermeidung von Mückenstichen in Endemiegebieten.

DENV ist weltweit in den Tropen und Teilen der Subtropen endemisch (Dengue-Risiko-Karte in [7]). Außer einem Fall einer nosokomialen Übertragung [9] ist kein weiterer Fall einer DENVTransmission auf deutschem Boden bekannt. Jedoch infizieren sich immer wieder in Deutschland lebende Personen im Ausland, zumeist in den klassischen Endemiegebieten der Tropen und Subtro- 
pen. Allerdings kam es in den letzten Jahren auch zur DENV-Übertragung in Südeuropa. So infizierte sich im Jahr 2010 ein deutscher Reisender in Süd-Kroatien [10]. Im gleichen Jahr wurde autochthone DENV-Übertragung in Südfrankreich belegt [11]. Vektor war in diesen Fällen wohl Aedes albopictus, die mittlerweile in vielen Regionen Südeuropas etabliert ist [12]. Im Herbst 2012 kam es auf der zu Portugal gehörenden Atlantikinsel Madeira zu einem Denguefieber-Ausbruch mit über 2000 Fällen [13], bei dem auch 78 europäische Reisende (19 Deutsche) betroffen waren [14]. Auf Madeira kommt Aedes aegypti vor [15].

Eine Meldepflicht für in Deutschland diagnostizierte Infektionen mit DENV besteht seit 2001 einerseits für den Labornachweis einer akuten DENV-Infektion (gemäß $\$ 7$ Abs. 1, IfSG, unabhängig vom Krankheitsbild als Nachweis eines anderen „Erregers hämorrhagischer Fieber“) sowie unabhängig vom Erreger für das in Deutschland diagnostizierte Krankheitsbild eines hämorrhagischen Fiebers (gemäß $\$ 6$, Abs. 1 Nr. 1 g, IfSG) [16]. Seit 2001 wurden in Deutschland meist jedes Jahr zwischen 60 und 300 Fälle von Denguefieber gemeldet; 2010 und 2012 waren es fast 600 Fälle (• Abb. 1), im Jahr 2013 wird diese Zahl noch deutlich überschritten. Die starken Schwankungen bei den Meldezahlen gehen wohl vor allem auf das periodisch schwankende Infektionsrisiko in beliebten Urlaubsgebieten zurück. In allen Jahren war Thailand das am häufigsten genannte Infektionsland, meist gefolgt von anderen Ländern in Süd- und Südostasien, Lateinamerika/Karibik. Diese Verteilung wird stark vom Reiseverhalten beeinflusst, und das Infektionsrisiko kann in einem kleinen, selten bereisten Land größer sein als im Pauschal-Fernreiseziel Thailand. Die Inzidenz von DENVInfektionen in Deutschland ist in der Altersgruppe 20 bis 40 Jahre am höchsten. Schwere Verläufe (0,4\% aller Fälle) werden nur selten übermittelt: 2001 bis 2012 gab es 8 DHF-Fälle und 5 DSS-Fälle; 12 der 13 Fälle hatten sich in asiatischen Ländern infiziert. Eine 21-jährige Patientin mit nachgewiesener DENV-Zweitinfektion verstarb im Zusammenhang mit einer Operation; [17] weitere Todesfälle wurden nicht bekannt.

Bundesgesundheitsbl 2014·57:557-567 DOI 10.1007/s00103-013-1925-9

(c) Springer-Verlag Berlin Heidelberg 2014

\section{Frank · M. Faber $\cdot$ W. Hellenbrand $\cdot$ H. Wilking $\cdot$ K. Stark Wichtige, durch Vektoren übertragene Infektionskrankheiten beim Menschen in Deutschland. Epidemiologische Aspekte}

\section{Zusammenfassung}

Humanpathogene, vektorübertragene Infektionserreger spielen für Deutschland eine bedeutende Rolle. Die endemischen, zoonotischen Infektionserreger sind entweder bundesweit verbreitet (Borrelia burgdorferi sensu latu) oder kommen in bestimmten geografischen Regionen vor (FSME-Viren, Hantaviren). Sie verursachen eine erhebliche Krankheitslast. Ihre Prävention und Kontrolle beruhen im Wesentlichen auf Aufklärung und persönlichen Schutzmaßnahmen (FSME-Impfung, Schutz vor Vektoren). Eine gute Surveillance, ergänzt um gezielte epidemiologische Studien, ist Voraussetzung zur Bewertung der räumlich-zeitlichen Infektionsrisiken und der Wirksamkeit von Präventionsmaßnahmen. Neben den endemischen Erregern müssen die importierten, durch Vektoren - zumeist Mücken - übertragenen Erreger im Rahmen der Surveillance-Aktivitäten ebenfalls systematisch und intensiv be- obachtet werden, zum einen, um das Risiko für Reisende aus Deutschland einschätzen zu können, zum anderen, um das Risiko einer möglichen autochthonen Übertragung adäquat bewerten zu können. Hierbei sind weitere Faktoren zu berücksichtigen (Etablierung von invasiven Mückenarten in Deutschland, zunehmende Erwärmung). Unter diesen Erregern sind vor allem das West-Nil-Virus, das Denguevirus, das Chikungunyavirus und der Malariaerreger (Plasmodien) zu nennen. Im vorliegenden Beitrag geben wir einen Überblick über die epidemiologische Situation bei ausgewählten, für Deutschland besonders relevanten, durch Vektor-übertragene Erreger ausgelösten Infektionskrankheiten.

\section{Schlüsselwörter}

Vektor-übertragene Infektionen.

Surveillance - Epidemiologie · Prävention . Mücken

\section{Important vector-borne infectious diseases among humans in Germany. Epidemiological aspects}

\section{Abstract}

Vector-borne infections pathogenic to humans play an important role in Germany. The relevant zoonotic pathogens are either endemic throughout Germany (e.g. Borrelia burgdorferi sensu latu) or only in specific regions, e.g. tick-borne encephalitis (TBE) virus and hantavirus. They cause a substantial burden of disease. Prevention and control largely rely on public advice and the application of personal protective measures (e.g. TBE virus vaccination and protection against vectors). High quality surveillance and targeted epidemiological studies are fundamental for the evaluation of temporal and spatial risks of infection and the effectiveness of preventive measures. Aside from endemic pathogens, vector-borne infections acquired abroad, mostly transmitted by mosquitoes, have to be systematical- ly and intensively monitored as well, to assess the risk of infection for German residents traveling abroad and to adequately evaluate the risk of autochthonous transmission. Related issues, such as invasive species of mosquitoes in Germany and climate change, have to be taken into consideration. Such pathogens include West Nile, dengue and chikungunya viruses, as well as malaria parasites (Plasmodium species). The article presents an overview of the epidemiological situation of selected relevant vector-borne infections in Germany.

\section{Keywords}

Vector-borne infections - Surveillance . Epidemiology · Prevention · Mosquitoes
Ob DENV auch in Deutschland übertragen werden kann, hängt maßgeblich von der Ansiedelung kompetenter Vektoren $\mathrm{ab}$, denn über virämische Reiserückkehrer steht das Virus hier zumindest punktuell ganzjährig zur Verfügung. Gelege und Einzelexemplare von Aedes albopictus wurden in Süddeutschland ge- funden $[18,19,20,21]$, jedoch konnte bislang keine etablierte Population nachgewiesen werden. Durch den Klimawandel bedingte wärmere und längere Sommer könnten regional einer dauerhaften Ansiedlung von Aedes albopictus Vorschub leisten. Somit sind ausgehend von virämischen Reisenden zwar einzelne auto- 
Tab. 1 An das RKI übermittelte Fälle symptomatischer Chikungunyafieber-Erkrankungen (nach RKI Referenzdefinition) ausgewertet nach den Ländern, in denen diese Infektionen erworben wurden (Mehrfachnennungen und fehlende Angabe möglich, $n=213$ ); Zeitraum: 2006 bis einschließlich 2012 ( $n=215)$

\begin{tabular}{|c|c|c|c|c|c|c|c|c|}
\hline & 2006 & 2007 & 2008 & 2009 & 2010 & 2011 & 2012 & Gesamt \\
\hline Fallzahl & 53 & 32 & 17 & 52 & 37 & 13 & 9 & 215 \\
\hline $\begin{array}{l}\text { Meistgenanntes } \\
\text { Infektionsland }\end{array}$ & Mauritius & Indien & $\begin{array}{l}\text { Sri } \\
\text { Lanka }\end{array}$ & $\begin{array}{l}\text { Male- } \\
\text { diven }\end{array}$ & Indien & Indien & $\begin{array}{l}\text { Philip- } \\
\text { pinen }\end{array}$ & \\
\hline \multicolumn{9}{|c|}{ Länder im Einzelnen (Nennungen) } \\
\hline Indien & 4 & 18 & 4 & 11 & 13 & 6 & 2 & 58 \\
\hline Mauritius & 34 & & & & & 1 & & 35 \\
\hline Malediven & & & 1 & 23 & 4 & & & 28 \\
\hline Sri Lanka & & 6 & 9 & 2 & 1 & & & 18 \\
\hline Indonesien & 2 & & & 1 & 10 & 2 & 2 & 17 \\
\hline Seychellen & 9 & 7 & 1 & & & & & 17 \\
\hline Thailand & & & 1 & 10 & 4 & 1 & & 16 \\
\hline Malaysia & 1 & & 1 & 4 & 1 & 1 & & 8 \\
\hline Philippinen & & & & 1 & & 1 & 3 & 5 \\
\hline Madagaskar & 2 & & & & 1 & & & 3 \\
\hline Kenia & & & 1 & & & 1 & & 2 \\
\hline Myanmar & & & & & 2 & & & 2 \\
\hline Singapur & & & 1 & 1 & & & & 2 \\
\hline China & & & & 1 & & & & 1 \\
\hline Kambodscha & & 1 & & & & & & 1 \\
\hline $\begin{array}{l}\text { Nennungen } \\
\text { gesamt }\end{array}$ & 52 & 32 & 19 & 54 & 36 & 13 & 7 & 213 \\
\hline
\end{tabular}

chthone Übertragungen dort denkbar, wo kompetente Vektoren existieren. Da jedoch auch die extrinsischen Inkubationszeiten (in der Mücke) klimaabhängig sind, wird die Übertragungsdynamik selbst bei für Deutschland hohen Sommertemperaturen begrenzt sein.

\section{Chikungunyafieber}

Das Chikungunyavirus (CHIKV, Alphavirus, Familie Togaviren) ist der Erreger des Chikungunyafiebers. Das Virus kann durch verschiedene Mückenarten übertragen werden; in Ausbrüchen werden in der Regel Aedes aegypti, neuerdings auch Aedes albopictus als wesentliche Vektoren beschrieben. Nach einer Inkubationszeit von 2 bis 10 Tagen [22] entwickelt sich ein von Fieber, Knochen- und Muskelschmerzen geprägtes Krankheitsbild [23, 24]). Weiterhin können Hautausschlag, leichte Haut- und Schleimhautblutungen sowie Gastroenteritis vorkommen. Das Fieber klingt meist nach wenigen Tagen $\mathrm{ab}$, die Muskel- und Gelenkschmerzen können aber lange, zum Teil 1 bis 2 Jahre, anhalten. Das Risiko für schwere Verläu- fe scheint mit zunehmendem Alter anzusteigen. Ein vergleichsweise mild verlaufendes hämorrhagisches Fieber wurde in seltenen Fällen beschrieben [25]. Die Erkrankung ist selbstlimitierend und fast nie tödlich. Impfstoffe oder spezifische Chemotherapeutika gegen Chikungunyafieber gibt es nicht. Präventiv wirksam ist nur die Vermeidung von Mückenstichen. Eine Meldepflicht für in Deutschland diagnostizierte Infektionen mit CHIKV besteht einerseits für den Labornachweis einer akuten CHIKVInfektion (gemäß $₫ 7$ Abs. 1, IfSG, unabhängig vom Krankheitsbild als Nachweis eines anderen „Erregers hämorrhagischer Fieber") sowie unabhängig vom Erreger, für das in Deutschland diagnostizierte Krankheitsbild eines hämorrhagischen Fiebers (gemäß $₫ 6$, Abs. $1 \mathrm{Nr}$. $1 \mathrm{~g}$, IfSG) [16].

Vor dem Jahr 2006 wurden dem RKI keine Fälle von CHIKV übermittelt (- Tab. 1). Allerdings wurden bei Tropenrückkehrern schon vorher serologisch CHIKV-Infektionen nachgewiesen (z. B. [26]). Die gemeldeten Fallzahlen waren vor allem in den Jahren 2006,
2007, 2009 und 2010 relativ hoch. In den Meldejahren 2006 bis einschließlich 2012 wurden 215 Fälle von Chikungunyafieber übermittelt. Die häufigsten Infektionsländer waren Indien, Mauritius, die Malediven, Sri Lanka, Indonesien, die Seychellen und Thailand. Europäische Infektionsländer wurden bislang nicht genannt. Betrachtet man die Altersverteilung der Fälle, zeigt sich, dass Kinder und Jugendliche kaum betroffen waren, $29 \%$ der Betroffenen waren junge Erwachsene (20 bis 39 Jahre), $50 \%$ waren 40 bis 59 Jahre und $18 \% \geq 60$ Jahre alt. Diese Muster sind beeinflusst durch die Altersverteilung der Reisenden bezogen auf die Infektionsländer. Bei insgesamt $18 \%$ der übermittelten Fälle wurde ein Krankenhausaufenthalt angegeben.

Die Hauptendemiegebiete für das Chikungunyafieber liegen bislang in Afrika und Asien. Seit ca. 2005 ist ein starkes Wiederaufflammen entsprechender Epidemien in Ländern rund um den Indischen Ozean zu beobachten [27]. Offenbar kam es im Jahr 2007 erstmalig in Europa, in der Emilia Romagna in Italien, bedingt durch die Einreise einer einzelnen, in Indien infizierten virämischen Person und das Vorhandensein lokaler Populationen von Aedes albopictus zu einem Ausbruch mit über 300 Fällen [28]. Auch in Südfrankreich wurden 2010 vereinzelt autochthone Übertragungen beobachtet [11]. Seit dem Jahresende 2013 werden erstmals auch CHIKV-Infektionen in Mittelamerika (insbesondere Kleine Antillen) berichtet. Eine weitere Ausbreitung auf den amerikanischen Kontinenten erscheint möglich. Bezüglich einer möglichen autochthonen Übertragung von CHIKV in Deutschland gilt im Prinzip das Gleiche wie für das DENV.

\section{West-Nil-Fieber}

Das West-Nil-Virus (WNV), ein Flavivirus, ruft das West-Nil-Fieber (WNF) hervor. Das WNV wird durch eine große Anzahl verschiedener Mücken übertragen, darunter die in Deutschland weit verbreitete "Gemeine Stechmücke“ Culex pipiens. Vögel spielen als Reservoir eine bedeutende Rolle im Transmissionszyklus des Virus [29]; Menschen und andere Säugetiere (z. B. Pferde) sind meist Fehlwirte und 


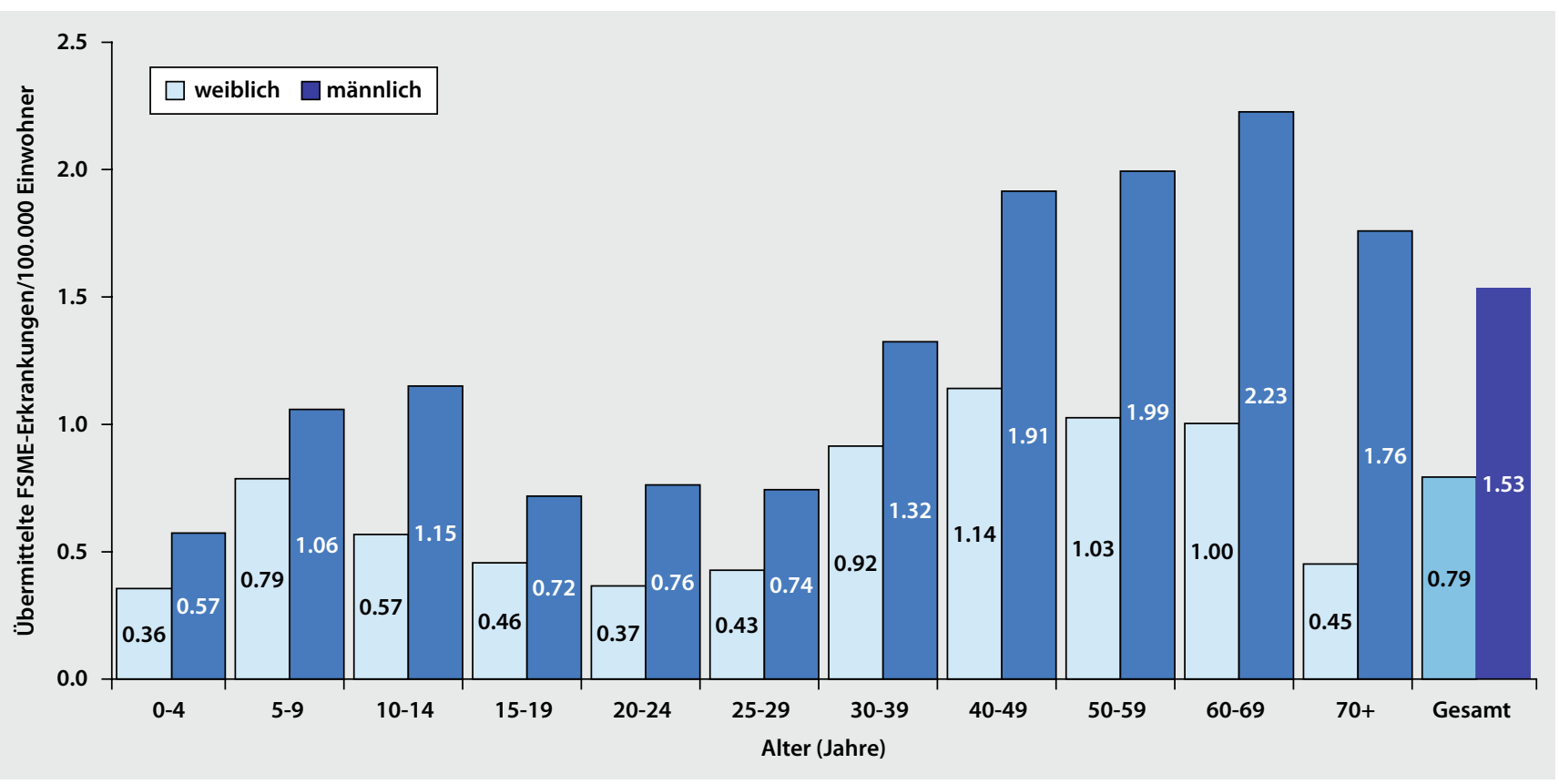

Abb. $2 \Delta$ Mittlere Jahresinzidenz der an das RKI übermittelten FSME-Erkrankungen in Bayern und Baden-Württemberg nach Alter und Geschlecht; Zeitraum: 2001-2012

als Virusquelle für die Mücken unbedeutend [30].

Die Inkubationszeit nach einer Infektion beträgt ca. 2 bis 14 Tage. Nur 20-25\% der Infizierten entwickeln Symptome. Die akut einsetzende Erkrankung äußert sich außer durch Fieber meist durch Symptome wie Kopfschmerzen, Schwächegefühl, Hautausschlag, Muskel-, Gelenk- und Augenschmerzen [30]. Die Erkrankungsdauer bzw. -schwere schwankt zwischen wenigen Tagen mit leichtem Krankheitsgefühl und einigen Monaten mit schweren gesundheitlichen Beeinträchtigungen. Etwa einer von 140 bis 240 West-Nil-FieberFällen entwickelt eine neuroinvasive Form (Meningitis, Enzephalitis), wobei dieses Risiko mit zunehmendem Alter stark ansteigt [31, 32, 33]. Zirka 9\% der Patienten mit neuroinvasiver Infektion versterben [34]. Risikofaktoren für einen tödlichen Verlauf sind fortgeschrittenes Alter, bestehende Vorerkrankungen, Immunschwäche und WNV-Enzephalitis. Impfstoffe gegen die WNV-Infektion gibt es nicht. Präventiv wirksam ist nur die Vermeidung von Mückenstichen in Endemiebzw. Ausbruchsgebieten. Eine Mückenbekämpfung kann den örtlichen Infektionsdruck vermindern.

Für WNV-Infektionen gibt es in Deutschland zurzeit keine spezifische
Meldepflicht. Allerdings sind Einzelfälle oder Häufungen von WNV-Erkrankung meldepflichtig, wenn sie als „bedrohliche Krankheit" eingeschätzt werden (gemäß $₫ 6$ Abs. 1 Nummer 5, IfSG), ebenso wie der gehäufte Nachweis von WNV im Labor, der auf „eine schwer wiegende Gefahr für die Allgemeinheit" hinweist (gemäß $\$$, Abs. 2, IfSG). Bedingt durch das unspezifische Krankheitsbild, werden viele - insbesondere leichter erkrankte - Fälle vermutlich nie als WNV-Infektion diagnostiziert. In Deutschland sind bislang nur 9 im Ausland erworbene WNV-Infektionen bekannt geworden: Insgesamt wurden 2003 (n=2), 2004 und 20074 immer in den USA erworbene - Infektionen gemeldet [35]. Der Fall einer 2011 in Kanada infizierten jungen Frau wurde publiziert [36]. 2012 wurden in Deutschland 4 importierte Infektionen gemeldet, erworben in Griechenland (Korfu), Montenegro, Ägypten und Tunesien [37]. Ohne eine spezifische Meldepflicht für WNVInfektionen sind diese Zahlen nicht als repräsentativ für die Gesamtsituation in Deutschland anzusehen. Möglicherweise hat das Wissen um aktuelle West-NilFieber-Ausbrüche und das selektive Testen von Reiserückkehrern aus den USA zur Diagnose der ersten Fälle geführt. Die 4 Fälle aus dem Mittelmeerraum im
Jahr 2012 - als Ausbrüche in diesen Ländern jeweils nicht allgemein bekannt waren - kann hingegen Ausdruck eines starken Infektionsdrucks im Vergleich zu den Vorjahren sein. Im Jahr 2013 wurde in Deutschland nur eine in Ungarn erworbene WNV-Infektion gemeldet.

Das WNV war ursprünglich nur in Teilen Afrikas und Eurasiens endemisch, wobei WNV-Infektionen außerhalb der Tropen nur saisonal im Spätsommer und Herbst auftreten. In Australien ist der Subtyp Kunjin-Virus verbreitet. Im Jahr 1999 kam es zum Eintrag von WNV in den bis dahin WNV-freien amerikanischen Kontinent im Raum New York [38]. Seitdem hat sich das Virus in ganz Nordamerika bis hinein nach Mittelamerika ausgebreitet und verursacht dort zum Teil massive saisonale Ausbrüche [34]. In den USA wurden seit 1999 mehrere tausend Todesfälle registriert. Für Ausbrüche von WNVErkrankungen beim Menschen und anderen Säugetieren (z. B. Pferden) im Mittelmeerraum spielt offenbar kleinräumig das Vorhandensein von Feuchtgebieten eine Rolle, in denen möglicherweise virämische Zugvögel rasten und viele Mücken vorhanden sind. Eine jeweils aktuelle Übersicht über Ausbrüche von West-NilFieber bzw. über Nachweise von WNV in Europa bieten die Webseiten des Euro- 


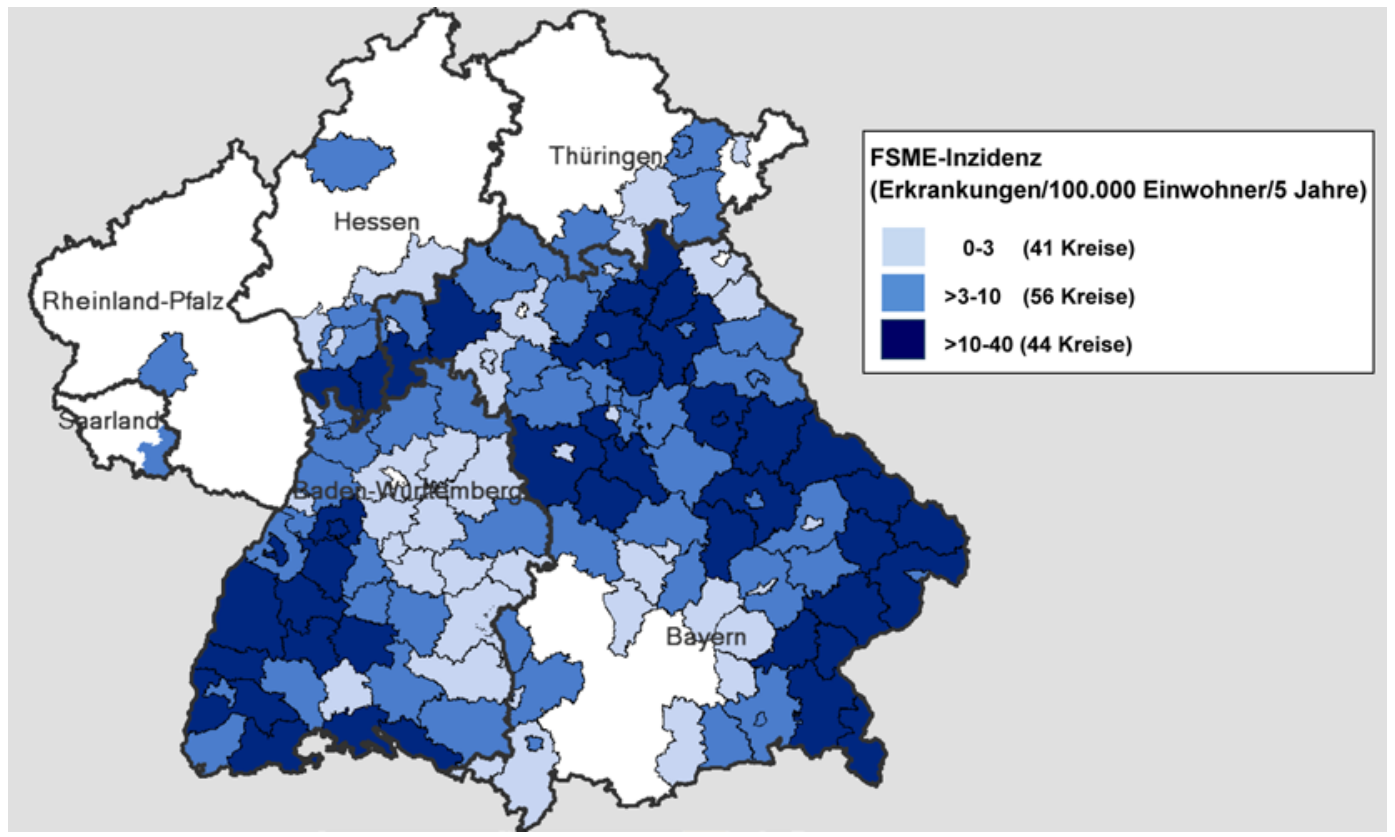

Abb. 3 A Bundesländer mit FSME-Risikogebieten im Jahr 2012 eingefärbt nach Höhe der FSME-Inzidenz. Zugrunde liegt immer die höchste Inzidenz, die im jeweiligen Kreis in einem der im Zeitraum 2002 bis 2012 enthaltenen 5-Jahres-Intervalle beobachtet wurde. Ein Kreis wird als FSME-Risikogebiet definiert, wenn die Anzahl der übermittelten FSME-Erkrankungen in den Zeiträumen 2002 bis 2006, 2003 bis 2007, 2004 bis 2008, 2005 bis 2009, 2006 bis 2010, 2007 bis 2011 oder 2008 bis $2012 \mathrm{im}$ Kreis ODER in der Kreisregion (bestehend aus dem betreffenden Kreis plus allen angrenzenden Kreisen) signifikant $(p<0,05)$ höher liegt als die bei einer Inzidenz von 1 Erkrankung pro 100.000 Einwohner erwartete Fallzahl. In den nicht dargestellten Bundesländern traten wenige Einzelfälle auf (Übersicht s. [64]), die jedoch nie zur Überschreitung der definierten Inzidenzgrenze führten

pean Center for Disease Prevention and Control (ECDC) [39].

Obwohl auch in Deutschland serologisch und virologisch bei Menschen, Pferden, Vögeln und Mücken nach Evidenz für WNV-Infektionen gesucht wurde, gibt es derzeit keinen Anhaltspunkt dafür, dass es hier zur WNV-Übertragung kommt [40, 41, 42, 43, 44, 45]. Dennoch scheinen auch in Deutschland zumindest einige Voraussetzungen für mögliche Ausbrüche von WNV-Erkrankungen vorzuliegen (Vorhandensein kompetenter WNV-Vektoren und von Zugvögeln mit Aufenthalten in Endemiegebieten). Für die Surveillance des West-Nil-Fiebers wäre die Einführung einer spezifischen Meldepflicht für WNV-Nachweise wichtig. Voraussetzung für belastbare Meldedaten wäre jedoch auch die routinemäßige Einleitung einer virologischen Erregersuche bei Fällen von aseptischer Enzephalitis und Meningitis, insbesondere bei älteren Erwachsenen im Spätsommer und Herbst. Eine wesentliche Vergrößerung des Verbreitungsgebietes von WNV, insbesondere in typischen Urlaubsländern rund um das Mittelmeer hat Konsequenzen für die Praxis der Blutspendentestung in Deutschland [46]. Schon jetzt werden Reiserückkehrer aus Regionen mit mehr als einer autochthonen WNV-Infektion für 4 Wochen von der Blutspende zurückgestellt oder mittels WNV-PCR getestet.

\section{Frühsommermeningo- enzephalitis (FSME)}

Das FSME-Virus (FSME-V, Gattung Flaviviren) verursacht die Frühsommermeningoenzephalitis (FSME). Es wird in Deutschland durch die Schildzecke Ixodes ricinus übertragen [47]. Zecken werden bei ca. $6^{\circ} \mathrm{C}$ aktiv [47]; daher sind Übertragungen vor allem zwischen Frühjahr und Herbst möglich. In seltenen Fällen kann die Krankheit auch durch den Verzehr von Rohmilch eines infizierten Tieres übertragen werden $[48,49,50,51,52]$. Die FSME kommt in weiten Teilen Zentral- und Osteuropas vor; das Endemiegebiet erstreckt sich über Sibirien und Teile Asiens bis an die pazifische Küste (FSMERisiko-Karte in [47]) [53].
Der typische Verlauf einer FSME-Erkrankung ist biphasisch. Sie beginnt mit unspezifischen, grippeähnliche Beschwerden (Inkubationszeit meist 7 bis 14 Tage, Spanne: 2 bis 28 Tage) [54, 55]. Nach einem kurzen Intervall von ca. 1 Woche treten spezifische Symptome der FSME mit Beteiligung des zentralen Nervensystems (ZNS) auf (Meningitis, Enzephalitis, Myelitis). Ein hoher Anteil der Infektionen verläuft jedoch asymptomatisch, oder die zweite Krankheitsphase bleibt aus, Schätzungen gehen von $70-95 \%$ aus $[47,56]$. Das Risiko für einen schweren Verlauf steigt mit dem Alter deutlich an [57, 58, 59, 60]. Die FSME-Impfung stellt neben schützender Kleidung und Repellents die wichtigste Schutzmaßnahme dar. Die beiden verfügbaren Impfstoffe sind sehr wirksam $[61,62]$ und ab dem Alter von einem Jahr zugelassen. Die Ständige Impfkommission (STIKO) empfiehlt die Impfung für Personen, die in Risikogebieten gegenüber Zecken exponiert sind [63]. Die FSME-Impfquoten in deutschen Risikogebieten sind in den letzten Jahren vor allem bei Kindern deutlich angestiegen, 


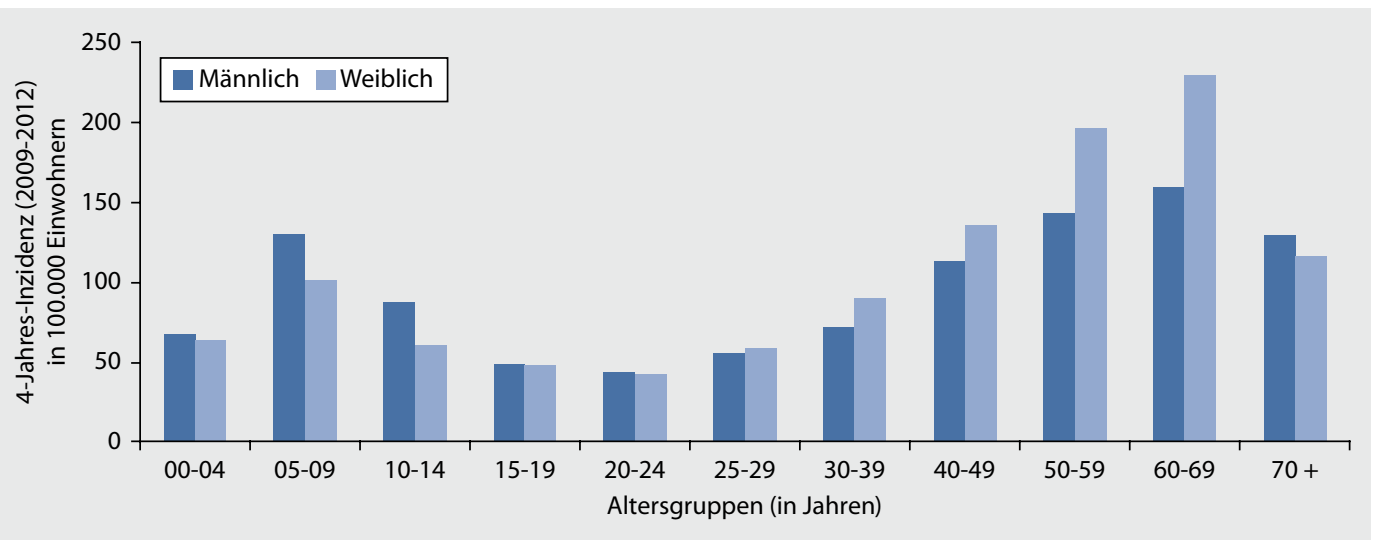

Abb. $4<$ Kumulative Inzidenz der in den Jahren 2009 bis 2012 aus den östlichen Bundesländern an das RKI übermittelten Erkrankungen an Lyme-Borreliose, ausgewertet nach Altersgruppen und Geschlecht

stagnieren aber in den letzten Jahren. Bei Erwachsenen bestehen noch große Impflücken [64].

Nach dem IfSG ist die FSME seit 2001 in Deutschland meldepflichtig. Die Erkrankungszahlen zeigen eine ausgeprägte Saisonalität: Im Zeitraum von 2001 bis 2012 traten 58\% der Fälle im 3. Jahresquartal auf, 25\% im 2. und 16\% im 4. Quartal. Die Inzidenz schwankt $z$. T. stark von Jahr zu Jahr. Bundesweit lag die Zahl der jährlich übermittelten FSME-Erkrankungen zwischen 195 (2012) und 546 (2006) (Mittelwert 312 Fälle). Die Mehrzahl der Fälle $(86 \%)$ trat in den beiden Bundesländern Bayern und Baden-Württemberg auf; hier lag die mittlere Jahresinzidenz bei 1,2 Erkrankungen/100.000 Einwohner. Die Schwankungen der Fallzahlen ergeben sich aus dem Zusammenspiel verschiedener Einflüsse. So wirken sich klimatische und ökologische Faktoren sowohl auf die Aktivität und den Lebenszyklus der Zecken als auch auf die Wirtstierpopulation aus. Das Risiko für eine Zeckenexposition hängt wiederum vom wetterabhängigen Freizeitverhalten der Menschen ab. Nicht zuletzt kann auch das Diagnose- und Meldeverhalten eine Rolle spielen. Die FSMEInzidenz liegt vor allem in östlichen Ländern Europas wie Slowenien, dem Baltikum und Tschechien sowie Teilen von Russland deutlich höher als in Deutschland [53]. Dies galt auch für Österreich, jedoch konnte dort die Inzidenz aufgrund hoher Impfquoten seit den 1980er-Jahren deutlich gesenkt werden [62]. In allen betroffenen Ländern schwankt die Inzidenz regional sehr stark.

Die FSME kommt häufiger bei männlichen als bei weiblichen Personen vor (- Abb. 2). Ob dies auf eine höhere kli- nische Manifestationsrate bei Männern oder auf ein $z$. B. verhaltensbedingtes oder beruflich bedingtes höheres Infektionsrisiko zurückzuführen ist, ist unklar, da derartige Daten gemäß IfSG nicht erhoben werden. Die altersspezifische Inzidenz hat einen ersten Gipfel bei 5- bis 14-jährigen Kindern und steigt ab der 4. Lebensdekade wieder deutlich an mit einem zweiten Gipfel in der 7. Lebensdekade (• Abb. 2). Im Zeitraum 2001 bis 2012 wurde bei $44 \%$ der übermittelten Fälle eine ZNS-Symptomatik angegeben $(27 \%$ bei Kindern im Alter von $<5$ Jahren). Die Gesamtletalität lag bei $0,5 \%$; bei Personen in einem Alter von $\geq 70$ Jahren jedoch bei $2,5 \%$.

Die Meldedaten bilden die Grundlage zur Ausweisung von FSME-Risikogebieten. Seit 2007 basiert diese auf der Bewertung der kreisbezogenen FSME-Inzidenz unter Einbeziehung der Inzidenz in umliegenden Kreisen ([65] und 3). Die FSME ist in Deutschland überwiegend auf den süddeutschen Raum begrenzt; eine starke Ausbreitung in andere Regionen wurde bislang nicht beobachtet. Dies reflektiert vermutlich, dass eine nachhaltige Etablierung des FSME-Virus in einem Naturherd spezifischerer Bedingungen bedarf $[66,67]$ als bei der Lyme-Borreliose [68]. So ist die Durchseuchung von Zecken mit dem FSME-Virus gering; in einer Übersicht von Zeckenuntersuchungen in Deutschland zwischen 1990 und 2010 lag sie meist bei $<2 \%$ mit einer Spanne von $0-5,2 \%$; höhere Werte wurden allerdings in gesogenen Zecken beobachtet [69]. FSME-Risikogebiete befinden sich in Baden-Württemberg, Bayern, Südhessen, Thüringen und vereinzelt in Rheinland-Pfalz und dem Saarland (• Abb. 3). Die FSME-Inzidenz in den Risikogebieten ist am höchsten an den Grenzen zu Österreich, Tschechien und der Schweiz, im westlichen Baden-Württemberg entlang des Rheins, in Südhessen sowie in nördlicheren Regionen Baden-Württembergs und Bayerns ( $\bullet$ Abb.3). In den letzten Jahren kamen nur vereinzelt Risikogebiete hinzu; diese grenzten alle - mit Ausnahme des Saar-Pfalz-Kreises im Saarland an bestehende Risikogebiete an.

Sporadisch treten FSME-Erkrankungen jedoch auch außerhalb der Risikogebiete auf. Vor allem aus Sachsen werden immer wieder Fälle gemeldet, besonders aus Gebieten, die an tschechische Kreise mit relativ hoher FSME-Inzidenz grenzen. Daher sollte eine FSME-Impfung erfolgen, wenn Aufenthalte in diesen Gebieten geplant sind. Einzelfälle wurden auch aus anderen Bundesländern berichtet [64]. Zudem war die FSME in den 1960 er- und 1970er-Jahren in den neuen Bundesländern verbreitet [70]. Warum hier seitdem nur noch Einzelfälle aufgetreten sind, ist unklar. Bei entsprechender klinischer Symptomatik sollte daher auch außerhalb der ausgewiesenen Risikogebiete eine sorgfältige FSME-Diagnostik erfolgen, insbesondere während der Zeckensaison.

\section{Lyme-Borreliose}

Die Lyme-Borreliose ist in den gemäßigten Breiten der nördlichen Hemisphäre verbreitet und in Mitteleuropa die häufigste durch Vektoren übertragene Infektionskrankheit. Sie wird durch Bakterien der Spezies Borrelia (B.) burgdorferi sensu lato (s. l.) ausgelöst. Es gibt mindestens 5 humanpathogene Genospezies: B. burgdorferi sensu stricto, B. garinii, B. afzelii, 


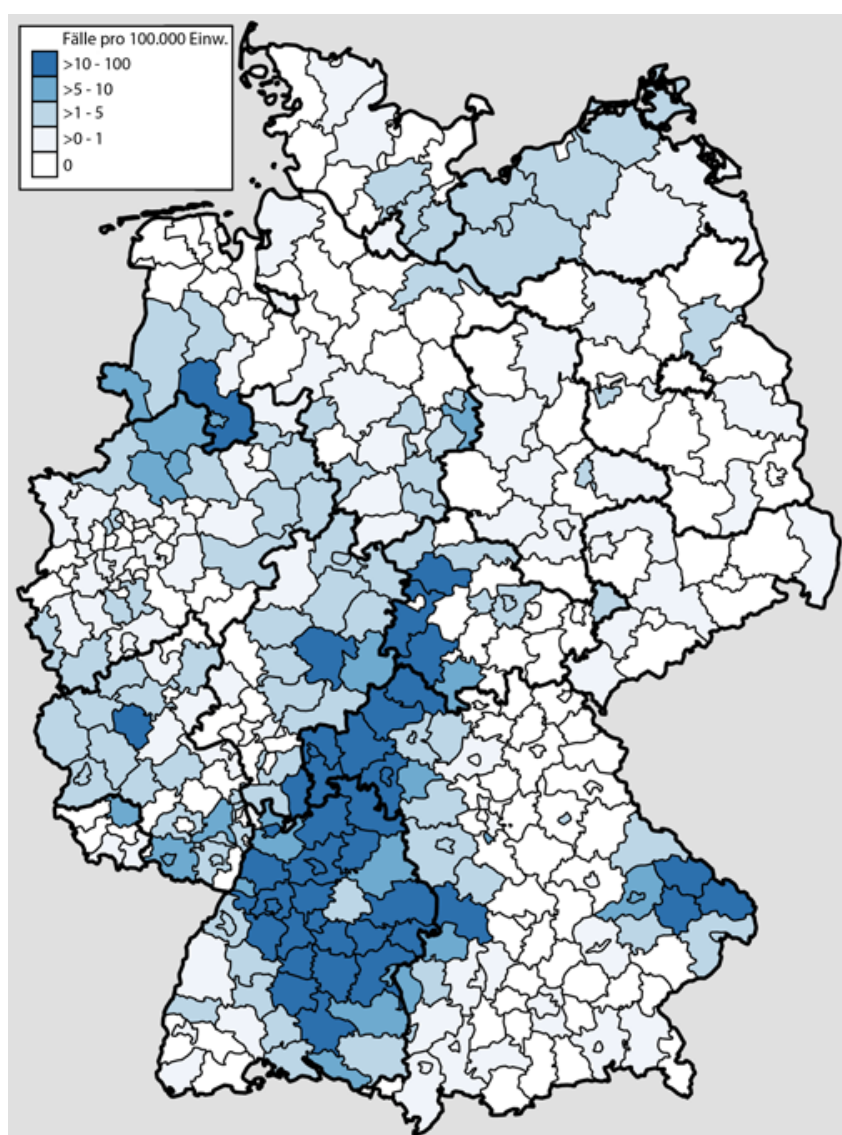

Abb. $5<$ An das RKI übermittelte Hantavirus-Erkrankungen (nach RKI-Referenzdefinition) pro 100.000 Einwohner nach Kreis, Deutschland, 2012
B. bavariensis und B. spielmanii [71]. In Europa sind vor allem die ersten 3 Genospezies endemisch. Übertragender Vektor in Mitteleuropa ist die Zecke Ixodes ricinus (Gemeiner Holzbock). Die Erreger zirkulieren zwischen den Schildzecken und ihren Wirten, insbesondere Nagetiere und einige Vogelarten. Rehwild und Rotwild sind für die Aufrechterhaltung signifikanter Zeckenpopulationen bedeutend, erkrankten aber selbst nicht [72, 73]. Ixodes ricinus durchläuft 4 Entwicklungsstadien: Ei, Larve, Nymphe und adulte Zecke. Die durchschnittliche Erregerprävalenz ist bei adulten Zecken (16,8\%) höher als bei Nymphen $(10,1 \%)$ [74].

Die Lyme-Borreliose kann unterschiedliche Organe wie Haut, Gelenke, Herz, Auge oder Nervensystem betreffen. Der Verlauf wird in Stadien eingeteilt, und die Erkrankung kann in jedem Stadium selbstlimitierend sein. Eine frühe kutane Manifestation ist das Erythema migrans, eine mehrere Tage bis wenige Wochen nach Zeckenstich sich ringförmig ausbreitende Rötung. Neurologische Manifestationen kommen im frühen und späten Stadium vor. Sie schließen Meningitiden, Hirnnervenlähmungen und auch Störungen entlang peripherer Nerven ein (Neuroborreliose) [75, 76]. Weitere, in Europa eher selten beobachtete Manifestationsformen sind Lyme-Arthritis, Lyme-Karditis, das Borrelien-Lymphozytom und die chronisch fortschreitende Hauterkrankung (Akrodermatitis chronica atrophicans) [77]. Es existiert eine wirksame antibiotische Therapie.

Derzeit ist von einer endemischen Infektionsgefährdung durch Borrelia burgdorferi s.l. in allen Teilen Deutschlands und allen angrenzenden Ländern auszugehen $[78,79,80]$.

Auf Bundesebene existiert nach IfSG keine Meldepflicht für die Lyme-Borreliose. Die Auswertung der seit über 20 Jahren bestehenden länderspezifischen Meldepflicht in 6 ostdeutschen Bundesländern (Berlin, Brandenburg, Mecklenburg-Vorpommern, Sachsen, SachsenAnhalt und Thüringen) bietet Einblicke in zeitliche Trends und besonders betroffene Bevölkerungsgruppen [81, 82]. Zwischen den Jahren 2009 und 2012 wurden in Ostdeutschland insgesamt 18.894 Fälle gemeldet. Die Inzidenz ist besonders hoch bei älteren Erwachsenen; einen zweiten Gipfel hat sie bei Kindern im Alter von 5 bis 9 Jahren (• Abb. 4).

Die akute Lyme-Borreliose zeigt aufgrund der temperaturabhängigen Aktivität der Zecken eine ausgeprägte Saisonalität. Die Inzidenz steigt ab April mit einem Höhepunkt im August an und fällt danach wieder ab. In Mecklenburg-Vorpommern wurde zwischen 2005 und 2011 ein stark zunehmender Trend beobachtet (Anstieg von 21,9 Fällen pro 100.000 Einwohner auf 74,8 Fälle). Die Meldeinzidenz im benachbarten Brandenburg fiel im gleichen Zeitraum von 90,1 auf 64,0 Fälle pro 100.000 Einwohner. Im Jahr 2012 war die Inzidenz überall ungewöhnlich niedrig. Die mit Abstand häufigste gemeldete Manifestation war das Erythema migrans (95\%). Eine akute Neuroborreliose betraf 630 Fälle $(3,3 \%)$ und eine Lyme-Arthritis 367 Fälle (2,0\%).

Unterschiede in der Aufmerksamkeit der Betroffenen und Ärzte, in der durchgeführten Labordiagnostik und der Intensität der Surveillance können die beobachteten Inzidenzunterschiede zum Teil erklären. Auch unterschiedliches Freizeitverhalten, berufliche Aktivitäten und veränderte ökologische Faktoren (Landschaftswandel, Klimawandel) beeinflussen die Borreliose-Häufigkeit.

Wertvolle Daten zur Verbreitung von Infektionen mit B. burgdorferi bieten die bundesweiten, repräsentativen Gesundheitssurveys. Blutproben aus dem vom RKI durchgeführten Kinder- und Jugendgesundheitssurveys (KiGGS, 2003-2006, Alter 0 bis 17 Jahre) wurden auf Antikörper gegen B. burgdorferi untersucht [78, 83]. Die Seroprävalenz bei den Teilnehmern ( $\mathrm{n}=12.614)$ betrug 4,0\% (95\%-Vertrauensintervall: 3,6-4,5\%). Sie stieg kumulativ mit dem Alter an. Bei männlichen Teilnehmern war die Seroprävalenz signifikant höher als bei weiblichen. Teilnehmer im Süden von Deutschland und solche aus ländlichen Gebieten oder Kleinstädten wiesen eine höhere Seroprävalenz auf. Kinder mit Migrationshintergrund hatten eine deutlich geringere Seroprävalenz. Das Halten einer Katze war mit einer erhöhten Seroprävalenz verbunden, nicht aber das Halten anderer Haustiere. 
Die Aufklärung der Bevölkerung und der Ärzteschaft über Maßnahmen zur Vermeidung eines Zeckenstichs und der nachfolgenden Infektion ist derzeit die einzige wirksame Präventionsmaßnahme [84]. Die Gefahr für Zeckenstiche besteht bei Aufenthalten im Freien mit Kontakt zu bodennahen Pflanzen. Eine Bekleidung, die möglichst viel Körperoberfläche bedeckt, reduziert das Risiko. Repellenzien wirken für eine kurze Zeit $(<2 \mathrm{~h})$ auch gegen Zecken. Nach Aufenthalten in Gebieten mit potenziellem Zeckenvorkommen während der Saison sollte der Körper (vor allem auch bei Kindern) sorgfältig nach Zecken abgesucht werden. Bei Zeckenbefall sollte die Zecke schnellstmöglich und fachgerecht entfernt werden [84]. Das Risiko für eine Borrelien-Übertragung ist in den ersten Stunden nach Befall sehr gering und erhöht sich nach ungefähr $18 \mathrm{~h}$ stark. Aktive und passive Immunisierungen stehen für Europa momentan nicht zur Verfügung.

\section{Hantavirus-Erkrankung}

Hantaviren sind RNA-Viren aus der Familie der Bunyaviridae (Genus Hantavirus). Sie kommen weltweit bei kleinen Säugetieren, insbesondere Nagetieren und Insektenfressern vor. Dabei ist eine Virusspezies (synonym: Virustyp) häufig mit einer ganz bestimmten Tierspezies assoziiert. Die geografische Verbreitung dieser Reservoirtiere bestimmt somit zum großen Teil das Vorkommen der jeweiligen Hantavirusspezies [85].

Humanmedizinisch relevant sind in Deutschland insbesondere das Puumalavirus (PUUV), übertragen durch die Rötelmaus (Myodes glareolus), und der Typ Kurkino des Dobrava-Belgrad-Virus (DOBV), übertragen durch die Brandmaus (Apodemus agrarius) [86]. Der Mensch infiziert sich in der Regel über das Aufwirbeln und Einatmen von Staub, der Exkremente von infizierten Reservoirtieren enthält, über den Kontakt verletzter Haut mit Exkrementen bzw. über den Verzehr kontaminierter Nahrungsmittel.

Nach Infektion mit einem der in Deutschland vorkommenden Hantavirustypen und einer Inkubationszeit von 2 bis 4 Wochen (maximal 5 bis 60 Tage) kann es zur Ausbildung eines Krankheits- bildes kommen, das mit dem Oberbegriff „hämorrhagisches Fieber mit renalem Syndrom" (HFRS) bezeichnet wird. Im Gegensatz zum Vollbild des HFRS, das regelmäßig bei Infektionen mit in Asien vorkommenden Virustypen auftritt und mit schweren Nierenfunktionsstörungen und vermehrter Blutungsneigung einhergeht, ist die durch PUUV und DOBV hervorgerufene Form milder. Sie wird auch als Nephropathia epidemica bezeichnet. Im Vordergrund stehen abrupt einsetzende grippeähnliche Symptome, häufig gefolgt von Lumbalgien, gastrointestinalen Symptomen und Sehstörungen. Die Nierenfunktionsstörung präsentiert sich mit Hämaturie, Proteinurie und Nierenversagen, das eine vorübergehende Dialyse erfordern kann. Hämorrhagien treten nur sehr selten auf. Die Letalität liegt bei PUUV-Infektionen bei unter 0,1\% [87].

$\mathrm{Zu}$ den Risikofaktoren für eine Infektion, die vorwiegend im Rahmen von epidemiologischen Fall-Kontroll-Studien ermittelt wurden, zählen Aktivitäten in den Endemiegebieten, die zum Kontakt mit Nagetieren und/oder deren Ausscheidungen führen, z. B. das Reinigen von Räumen, in denen Nagetiere vorkommen, Gartenarbeiten, Holzschlagen, Zelten, Arbeiten in der Forstwirtschaft oder im Bauwesen [88, 89]. Hantavirus-Erkrankungen treten in allen Altersgruppen auf, sind jedoch bei Kindern sehr selten. Am häufigsten wird die Erkrankung bei Männern im berufstätigen Alter beobachtet. Eine spezifische medikamentöse Therapie oder eine prophylaktische Impfung steht in Deutschland nicht zur Verfügung. Die wirksamste Präventionsmaßnahme besteht in der Expositionsprävention (Vermeiden des Kontakts zu Nagetieren oder virushaltigem Staub). Bei unvermeidbarer Exposition werden hygienische Barrieremaßnahmen (z. B. Handschuhe, partikelfiltrierende Halbmasken) empfohlen.

Eine Meldepflicht besteht in Deutschland einerseits für den direkten oder indirekten Labornachweis einer akuten Hantavirus-Infektion (gemäß $\$ 7$ Abs. 1, IfSG), sowie unabhängig vom Erreger, für das in Deutschland diagnostizierte Krankheitsbild eines hämorrhagischen Fiebers (gemäß $₫ 6$, Abs. 1 Nr. 1 g, IfSG) [16].

In den letzten Jahren variierte die Zahl der an das RKI übermittelten Hantavi-
rus-Infektionen sehr stark. Während in den Jahren 2008, 2009 und 2011 im Mittel jährlich 243 Fälle übermittelt wurden, waren in den Ausbruchsjahren 2007, 2010 und 2012 die Zahlen mit 1687, 2016 und 2825 übermittelten Fällen deutlich höher. Als Ursache für diese PUUV-Ausbrüche kommen am ehesten eine sehr starke lokale Zunahme der Populationsdichte und Durchseuchung des Tierreservoirs (der Rötelmäuse) in Betracht [86, 88, 89, 90, 91, $92,93]$. Betroffen waren jeweils insbesondere der Süden und Westen Deutschlands mit einer Inzidenz von bis zu 90 Neuerkrankungen pro 100.000 Einwohnern auf Kreisebene (• Abb. 5). Die Inzidenz und das Infektionsrisiko kann auch innerhalb eines Kreises sehr unterschiedlich sein [94].

Insgesamt ist bei einer noch relativ kurzen verfügbaren Zeitreihe von 12 Jahren nach Einführung des IfSG ein Trend hin zu häufigeren Ausbrüchen, höheren Fallzahlen pro Ausbruchsjahr und möglicherweise auch eine Ausweitung der betroffenen Gebiete („Endemiegebiete“) zu verzeichnen. Bei all diesen Beobachtungen kann jedoch auch das Diagnose- und Meldeverhalten eine große Rolle spielen. Insofern sind Projektionen zum Verlauf der jährlichen Erkrankungszahlen nicht mit ausreichender Sicherheit möglich.

\section{Schlussfolgerungen}

Die Surveillance der in Deutschland meldepflichtigen Vektor-übertragenen Infektionserreger hat sich bisher als effizient erwiesen. Sie erlaubt zum einen die Langzeitüberwachung endemischer Infektionserreger (räumlich-zeitliche Dynamik etc.), und sie liefert die Grundlage für vertiefende epidemiologische Studien zu den lokal bedeutsamen Risikofaktoren für ihr Auftreten (z. B. Hantaviren) und Hinweise für die Prävention (z. B. FSME). Veränderungen in der Häufigkeit von Infektionen durch diese Erreger (lokale Häufungen, Ausbreitung auf weitere geografische Gebiete) können rasch erkannt werden. Zum anderen erfasst die Surveillance Trends bei importierten Infektionskrankheiten wie Malaria, Dengue- oder Chikungunyafieber (einschließlich Veränderungen bei der Bedeutung einzelner Reiseländer als In- 
fektionsort). Allerdings ist insbesondere bei den mit Fieber einhergehenden Arbovirosen aufgrund der häufig nicht veranlassten Diagnostik von einer deutlichen Untererfassung auszugehen. Die Gefahr für autochthone Übertragungen von Dengue- oder Chikungunyaviren ist derzeit als äußert gering einzuschätzen. Damit solche Erkrankungsfälle überhaupt erkannt werden können, ist eine bessere diesbezügliche Aus- und Weiterbildung von Medizinern erforderlich. Wegen der fehlenden Meldepflicht für Infektionen mit WNV ist die Datenlage zum West-Nil-Fieber in Deutschland unvollständig. Bisher gibt es keinerlei Hinweise auf eine autochthone Übertragung von WNV in Deutschland. Die Einführung einer entsprechenden Meldepflicht (für Arbovirosen) sowie eine erhöhte diagnostische Aufmerksamkeit bei Vorliegen eines klinischen Verdachtsbildes (z. B. unklare Meningoenzephalitis) sowie die konsequente Erhebung von Reiseanamnesen würden die diesbezügliche Datenlage deutlich verbessern. Auch würden damit erste autochthone Fälle von WestNil-Fieber wahrscheinlich schneller erfasst werden. Um potenzielle Risiken für den Menschen durch Vektor-übertragene Erreger besser einschätzen zu können, ist für Deutschland ein gezieltes und systematisches Monitoring der Vektoren für diese Erreger (insbesondere von invasiven Stechmückenarten, aber regional auch der Populationsdichte und Erregerdurchseuchung von relevanten Nagetierund Zeckenarten) erforderlich.

\section{Korrespondenzadresse}

Prof. Dr. K. Stark

Robert Koch-Institut, FG35

Seestr. 10, 13353 Berlin

starkk@rki.de

\section{Einhaltung ethischer Richtlinien}

Interessenkonflikt. C. Frank, M. Faber, W. Hellenbrand, H. Wilking und K. Stark geben an, dass kein Interessenkonflikt besteht.

Dieser Beitrag beinhaltet keine Studien an Menschen oder Tieren.

\section{Literatur}

1. White NJ, Pukrittayakamee S, Hien TT et al (2013) Malaria. Lancet 383:723-735

2. Robert Koch-Institut (2013) Infektionsepidemiologisches Jahrbuch meldepflichtiger Krankheiten für 2012. Berlin

3. Stark K, Schoneberg I (2012) Increase in malaria cases imported from Pakistan to Germany in 2012. Euro Surveill 17:pii:20320

4. Kronefeld M, Dittmann M, Zielke D et al (2012) Molecular confirmation of the occurrence in Germany of Anopheles daciae (Diptera, Culicidae). Parasit Vectors 5:250

5. Weitzel T, Gauch C, Becker N (2012) Identification of Anopheles daciae in Germany through ITS2 sequencing. Parasitol Res 111:2431-2438

6. Krüger A, Rech A, Su XZ, Tannich E (2001) Two cases of autochthonous Plasmodium falciparum malaria in Germany with evidence for local transmission by indigenous Anopheles plumbeus. Trop Med Int Health 6:983-985

7. Simmons CP, Farrar JJ, Nguyen VV, Wills B (2012) Dengue. N Engl J Med 366:1423-1432

8. Guzman MG, Alvarez M, Halstead SB (2013) Secondary infection as a risk factor for dengue hemorrhagic fever/dengue shock syndrome: an historical perspective and role of antibody-dependent enhancement of infection. Arch Virol 158:1445-1459

9. Wagner D, With K de, Huzly D et al (2004) Nosocomial acquisition of dengue. Emerg Infect Dis 10:1872-1873

10. Schmidt-Chanasit J, Haditsch M, Schoneberg I et al (2010) Dengue virus infection in a traveller returning from Croatia to Germany. Euro Surveill 15:pii: 19677

11. Gould EA, Gallian P, De Lamballerie X, Charrel RN (2010) First cases of autochthonous dengue fever and chikungunya fever in France: from bad dream to reality! Clin Microbiol Infect 16:1702-1704

12. European Centre for Disease Prevention and Control (ECDC) (2013) VBORNET maps - mosquitoes. Aedes albopictus - Current known distribution: March 2013. http://ecdc.europa.eu/en/activities/ diseaseprogrammes/emerging_and_vector_borne_diseases/Publishinglmages/aedes-albopictusmaps-distribution-march-2013-high-res.jpg

13. Governo Regional da Madeira - Instituto de Administração da Saúde e Assuntos Sociais (2013) Communicado do Director-Geral da Saúde. Surto de dengue na llha da Madeira - situação em 19 de maio de 2013 (auf Portugiesisch, verfügbar unter http://www.dgs.pt/?cn=683368347243AAAAAAAAAAAA)

14. Frank C, Hohle M, Stark K, Lawrence J (2013) More reasons to dread rain on vacation? Dengue fever in 42 German and United Kingdom Madeira tourists during autumn 2012. Euro Surveill 18:20446

15. Almeida AP, Goncalves YM, Novo MT et al (2007) Vector monitoring of Aedes aegypti in the Autonomous Region of Madeira, Portugal. Euro Surveill 12:E071115 071116

16. Bundesrepublik Deutschland (2001) Infektionsschutzgesetz (IfSG). http://www.gesetze-im-internet.de/bundesrecht/ifsg/gesamt.pdf

17. Schmidt-Chanasit J, Tenner-Racz K, Poppert D et al (2012) Fatal dengue hemorrhagic fever imported into Germany. Infection 40:441-443

18. Pluskota B, Storch V, Brauneck T et al (2008) First record of Stegomyia albopicta (Skuse) (Diptera: Culicidae) in Germany. Eur Mosq Bull 26:1-5
19. Becker N, Geier M, Balczun C et al (2013) Repeated introduction of Aedes albopictus into Germany, July to October 2012. Parasitol Res 112:1787-1790

20. Kampen H, Kronefeld M, Zielke D, Werner D (2013) Further specimens of the Asian tiger mosquito Aedes albopictus (Diptera, Culicidae) trapped in southwest Germany. Parasitol Res 112:905-907

21. Werner D, Kronefeld M, Schaffner F, Kampen $H$ (2012) Two invasive mosquito species, Aedes albopictus and Aedes japonicus japonicus, trapped in south-west Germany, July to August 2011. Euro Surveill 17:pii: 20067

22. Fourie ED, Morrison JG (1979) Rheumatoid arthritic syndrome after chikungunya fever. S Afr Med J 56:130-132

23. Burt FJ, Rolph MS, Rulli NE et al (2012) Chikungunya: a re-emerging virus. Lancet 379:662-671

24. Thiberville SD, Moyen N, Dupuis-Maguiraga L et al (2013) Chikungunya fever: epidemiology, clinical syndrome, pathogenesis and therapy. Antiviral Res 99:345-370

25. Borgherini G, Poubeau P, Staikowsky F et al (2007) Outbreak of chikungunya on Reunion Island: early clinical and laboratory features in 157 adult patients. Clin Infect Dis 44:1401-1407

26. Schwarz TF, Jager G, Gilch S et al (1996) Travelrelated vector-borne virus infections in Germany. Arch Virol Suppl 11:57-65

27. Frank C, Schoneberg I, Stark K (2011) Trends in imported chikungunya virus infections in Germany, 2006-2009. Vector Borne Zoonotic Dis 11:631-636

28. Angelini R, Finarelli AC, Angelini P et al (2007) Chikungunya in north-eastern Italy: a summing up of the outbreak. Euro Surveill 12:E071122 071122

29. Wheeler SS, Vineyard MP, Woods LW, Reisen WK (2012) Dynamics of West Nile virus persistence in House Sparrows (Passer domesticus). PLoS Negl Trop Dis 6:e1860

30. Zou S, Foster GA, Dodd RY et al (2010) West Nile fever characteristics among viremic persons identified through blood donor screening. J Infect Dis 202:1354-1361

31. Mostashari F, Bunning ML, Kitsutani PT et al (2001) Epidemic West Nile encephalitis, New York, 1999: results of a household-based seroepidemiological survey. Lancet 358:261-264

32. Carson PJ, Borchardt SM, Custer B et al (2012) Neuroinvasive disease and West Nile virus infection, North Dakota, USA, 1999-2008. Emerg Infect Dis 18:684-686

33. Petersen LR, Brault AC, Nasci RS (2013) West Nile virus: review of the literature. JAMA 310:308-315

34. Centers for Disease Control and Prevention (USA) (2013) West Nile virus disease cases and deaths reported to CDC by year and clinical presentation, 1999-2012. http://www.cdc.gov/westnile/resources/pdfs/cummulative/99_2012_CasesAndDeathsClinicalPresentationHumanCases.pdf

35. Robert Koch Institut (Berlin) (2001-2013) SurvNET - Datenbank der meldepflichtigen Infektionskrankheiten in Deutschland

36. Schultze-Amberger J, Emmerich P, Gunther $S$, Schmidt-Chanasit J (2012) West Nile virus meningoencephalitis imported into Germany. Emerg Infect Dis 18:1698-1700

37. Gabriel M, Emmerich P, Frank C et al (2013) Increase in West Nile virus infections imported to Germany in 2012. J Clin Virol 58:587-589

38. Nash D, Mostashari F, Fine A et al (2001) The outbreak of West Nile virus infection in the New York City area in 1999. N Engl J Med 344:1807-1814 
39. European Centre for Disease Prevention and Control (ECDC) (2013) West Nile fever maps. http:// ecdc.europa.eu/en/healthtopics/west_nile_fever/ West-Nile-fever-maps/Pages/index.aspx

40. Linke S, Muehlen M, Niedrig M et al (2008) Assessing the exposure of German and Austrian bird ringers to West Nile virus (Flavivirus) and evaluating their potential risk of infection. J Ornithol 149:271275

41. Linke S, Niedrig M, Kaiser A et al (2007) Serologic evidence of West Nile virus infections in wild birds captured in Germany. Am J Trop Med Hyg 77:358364

42. Seidowski D, Ziegler U, Ronn JA von et al (2010) West Nile virus monitoring of migratory and resident birds in Germany. Vector Borne Zoonotic Dis 10:639-647

43. Timmermann U, Becker N (2010) Mosquito-borne West Nile virus (WNV) surveillance in the Upper Rhine Valley, Germany. J Vector Ecol 35:140-143

44. Ziegler U, Angenvoort J, Klaus C et al (2013) Use of competition ELISA for monitoring of west nile virus infections in horses in Germany. Int J Environ Res Public Health 10:3112-3120

45. Ziegler U, Seidowski D, Angenvoort J et al (2012) Monitoring of West Nile virus infections in Germany. Zoonoses Public Health 59(Suppl 2):95-101

46. Arbeitskreis Blut (2012) West-Nil-Virus - Stellungnahmen des Arbeitskreises Blut des Bundesministeriums für Gesundheit. Bundesgesundheitsbl 55:1024-1043

47. Lindquist L, Vapalahti $O$ (2008) Tick-borne encephalitis. Lancet 371:1861-1871

48. Holzmann H, Aberle SW, Stiasny K et al (2009) Tick-borne encephalitis from eating goat cheese in a mountain region of Austria. Emerg Infect Dis 15:1671-1673

49. Kerbo N, Donchenko I, Kutsar K (2005) Tickborne encephalitis outbreak in Estonia linked to raw goat milk, May-June 2005. Euro Surveill Wkly 10:E050623.050622. http://www.eurosurveillance. org/ew/052005/050623.asp\#050622

50. Hudopisk N, Korva M, Janet E et al (2013) Tickborne encephalitis associated with consumption of raw goat milk, Slovenia, 2012. Emerg Infect Dis 19:806-808

51. Caini S, Szomor K, Ferenczi E et al (2012) Tickborne encephalitis transmitted by unpasteurised cow milk in western Hungary, September to October 2011. Euro Surveill 17:pii=20128

52. Balogh Z, Ferenczi E, Szeles K et al (2010) Tickborne encephalitis outbreak in Hungary due to consumption of raw goat milk. J Virol Methods 163:481-485

53. Süss J (2011) Tick-borne encephalitis 2010: epidemiology, risk areas, and virus strains in Europe and Asia - an overview. Ticks Tick Borne Dis 2:2-15

54. Heymann DL (2008) Control of communicable diseases manual. American Public Health Association, Washington, D.C.

55. WHO (2011) Vaccines against tick-borne encephalitis: WHO position paper. Wkly Epidemiol Rec 86:241-256

56. Růžek D, Dobler G, Mantke OD (2010) Tick-borne encephalitis: Pathogenesis and clinical implications. Travel Med Infectious Disease 8:223-232

57. Kaiser R (2000) Epidemiologie und Verlauf der Frühsommer-Meningoenzephalitis in Baden-Württemberg zwischen 1994 und 1999. Dtsch Med Wochenschr 125:1147-1153

58. Kaiser R (2002) Tick-borne encephalitis (TBE) in Germany and clinical course of the disease. Int J Med Microbiol 291:58-61
59. Kaiser R (2004) Frühsommer-Meningoenzephalitis. Prognose für Kinder und Jugendliche günstiger als für Erwachsene. Dtsch Ärztebl 101:C1822-C1826

60. Kaiser R (2006) Frühsommermeningoenzephalitis im Kindes- und Jugendalter. Eine prospektive Studie über 10 Jahre in Baden-Württemberg und Südhessen. Monatsschr Kinderheilkd 154:1111-1115

61. Heinz FX, Holzmann H, Essl A, Kundi M (2007) Field effectiveness of vaccination against tick-borne encephalitis. Vaccine 25:7559-7567

62. Heinz FX, Stiasny K, Holzmann H et al (2013) Vaccination and tick-borne encephalitis, central Europe. Emerg Infect Dis 19:69-76

63. STIKO (2012) Mitteilung der Ständigen Impfkommission am Robert Koch-Institut (RKI). Empfehlungen der Ständigen Impfkommission (STIKO) am Robert Koch-Institut/Stand: Juli 2012. Epidemiol Bull 30:283-310

64. Robert Koch-Institut (2013) FSME: Risikogebiete in Deutschland (Stand: Mai 2013) Bewertung des örtlichen Erkrankungsrisikos. Epidemiol Bull 18:151162

65. Robert Koch-Institut (2007) Risikogebiete der Frühsommer-Meningoenzephalitis (FSME) in Deutschland. Epidemiol Bull 15:119-135

66. Randolph S, Miklisová D, Lysy J et al (1999) Incidence from coincidence: patterns of tick infestations on rodents facilitate transmission of tickborne encephalitis virus. Parasitology 118:177186

67. Randolph SE, Storey K (1999) Impact of microclimate on immature tick-rodent host interactions (Acari: Ixodidae): implications for parasite transmission. J Med Entomol 36:741-748

68. Robert Koch-Institut (2010) Zur Situation bei wichtigen Infektionskrankheiten in Deutschland LymeBorreliose: Analyse der gemeldeten Erkrankungsfälle der Jahre 2007 bis 2009 aus den sechs östlichen Bundesländern. Epidemiol Bull 12:101-107

69. Stefanoff P, Pfeffer M, Hellenbrand W et al (2013) Virus detection in questing ticks is not a sensitive indicator for risk assessment of tick-borne encephalitis in humans. Zoonoses Public Health 60:215-226

70. Süss J, Sinnecker H, Sinnecker R et al (1992) Epidemiology and ecology of tick-borne encephalitis in the eastern part of Germany between 1960 and 1990 and studies on the dynamics of a natural focus of tick-borne encephalitis. Zentralbl Bakteriol 277:224-235

71. Fingerle V, Schulte-Spechtel UC, Ruzic-Sabljic E et al (2008) Epidemiological aspects and molecular characterization of Borrelia burgdorferi s.l. from southern Germany with special respect to the new species Borrelia spielmanii sp. nov. Int J Med Microbiol 298:279-290

72. Gray JS, Kahl O, Robertson JN et al (1998) Lyme borreliosis habitat assessment. Zentralbl Bakteriol 287:211-228

73. Matuschka FR, Heiler M, Eiffert H et al (1993) Diversionary role of hoofed game in the transmission of Lyme disease spirochetes. Am J Trop Med Hyg 48:693-699

74. Rauter C, Hartung T (2005) Prevalence of Borrelia burgdorferi sensu lato genospecies in Ixodes ricinus Ticks in Europe: a meta analysis. Appl Environ Microbiol 71:7203-7216

75. Stanek G, Wormser GP, Gray J, Strle F (2012) Lyme borreliosis. Lancet 379:461-473

76. Strle F, Stanek G (2009) Clinical manifestations and diagnosis of lyme borreliosis. Curr Probl Dermatol 37:51-110
77. Stanek G, Fingerle V, Hunfeld KP et al (2011) Lyme borreliosis: clinical case definitions for diagnosis and management in Europe. Clin Microbiol Infect 17:69-79

78. Dehnert M, Fingerle V, Klier C et al (2012) Seropositivity of lyme borreliosis and associated risk factors: a population-based study in children and adolescents in Germany (KiGGS). PLoS One 7:e41321

79. Müller I, Freitag MH, Poggensee G et al (2012) Evaluating frequency, diagnostic quality, and cost of Lyme borreliosis testing in Germany: a retrospective model analysis. Clin Dev Immunol 2012:595427

80. Rizzoli A, Hauffe H, Carpi G et al (2011) Lyme borreliosis in Europe. Euro Surveill 16:pii: 19906

81. RKI (2010) Lyme-Borreliose: Analyse der gemeldeten Erkrankungsfälle der Jahre 2007 bis 2009 aus den sechs östlichen Bundesländern. Epid Bull 12:101-107

82. Wilking $\mathrm{H}$, Stark K (2014) Trends in surveillance data of human Lyme borreliosis from six federal states in eastern Germany, 2009-2012. Ticks Tick Borne Dis 5: 219-224

83. RKI (2012) Seroprävalenz der Lyme-Borreliose bei Kindern und Jugendlichen in Deutschland. Epidemiol Bull 14:113-120

84. RKI (2007) Ratgeber Infektionskrankheiten LymeBorreliose. Epidemiol Bull 17:147-150

85. Vaheri A, Henttonen $H$, Voutilainen L et al (2013) Hantavirus infections in Europe and their impact on public health. Rev Med Virol 23:35-49

86. Krüger DH, Ulrich RG, Hofmann J (2013) Hantaviruses as zoonotic pathogens in Germany. Dtsch Arztebl Int 110:461-467

87. Jonsson CB, Figueiredo LT, Vapalahti O $(2010)$ A global perspective on hantavirus ecology, epidemiology, and disease. Clin Microbiol Rev 23:412441

88. Abu Sin M, Stark K, Treeck U van et al (2007) Risk factors for hantavirus infection in Germany, 2005 Emerg Infect Dis 13:1364-1366

89. Winter $\mathrm{CH}$, Brockmann SO, Piechotowski l et al (2009) Survey and case-control study during epidemics of Puumala virus infection. Epidemiol Infect 137:1479-1485

90. Essbauer S, Schmidt J, Conraths FJ et al (2006) A new Puumala hantavirus subtype in rodents associated with an outbreak of nephropathia epidemica in South-East Germany in 2004. Epidemiol Infect 134:1333-1344

91. Hofmann J, Meisel H, Klempa B et al (2008) Hantavirus outbreak, Germany, 2007. Emerg Infect Dis 14:850-852

92. Ulrich R, Meisel H, Schutt M et al (2004) Prevalence of hantavirus infections in Germany. Bundesgesundheitsbl Gesundheitsforsch Gesundheitsschutz 47:661-670

93. Faber MS, Ulrich RG, Frank C et al (2010) Steep rise in notified hantavirus infections in Germany, April 2010. Euro Surveill 15:pii: 19574

94. Faber M, Wollny T, Schlegel M et al (2013) Puumala virus outbreak in Western Thuringia, Germany, 2010: epidemiology and strain identification. Zoonoses Public Health 60:549-554 